\title{
Model Making, An Interesting Method of Learning Anatomy: Students' perceptions
}

\section{Uma SV.}

Associate Professor, Department of Anatomy, Sapthagiri Institute of Medical Sciences and Research Centre, no. 15, Hesarghatta main road, navy layout, Chikkasandra, Chikkabanavara, Bangalore, Karnataka, India.

\section{ABSTRACT}

\begin{abstract}
Background: The knowledge of anatomy is very essential for the safe and efficient clinical practice. There has been a lot of efforts, made over recent years to promote active learning in students through innovative teaching techniques. Model making is one such type of active and self directed learning. The aim of the study is to introduce model making as a technique of learning Anatomy.The objective was to evaluate the students' perceptions about various aspects of model making, as a technique of learning anatomy

Material and Methods: Convenient sample of one hundred first year MBBS students were divided into four groups for different model making activities. Each group of twenty five was divided into six and nineteen. Group of nineteen did the routine dissection and the other of six did the model of structures under the cover of gluteus maximus, parotid gland, cavernous sinus with its relations or perineal pouches at various time intervals. Anonymous feedback was taken from students through a questionnaire using a Likert five-point grading scale. The number and percentage of students responding to each item was noted. The mean rating for each item was calculated.

Results: A majority of students were positive about the use of model making in anatomy. $94 \%, 93 \%$, and $91 \%$ of the students felt that model making was useful in learning anatomy,should be used for teaching other topics also and helped in long term memory respectively.

Conclusion: Students perceived that model making when used along with dissection would promote meaningful learning and deep understanding of anatomy.

KEY WORDS: Model making, Anatomy, Self directed learning, Active learning.
\end{abstract}

Corresponding Author: Dr. Uma SV, Associate Professor, Department of Anatomy, Sapthagiri Institute of Medical Sciences and Research Centre, no. 15, Hesarghatta main road, navy layout, Chikkasandra, Chikkabanavara, Bangalore, Karnataka, India.

E-Mail: drsvuma@gmail.com

Access this Article online Quick Response code

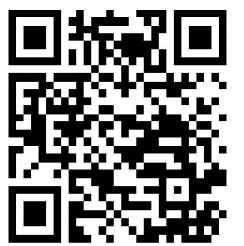

DOI: $10.16965 /$ ijar.2021.210

Journal Information

International Journal of Anatomy and Research

ISSN (E) 2321-4287 | ISSN (P) 2321-8967

https://www.ijmhr.org/ijar.htm

DOI-Prefix: https://dx.doi.org/10.16965/ijar

Article Information

Received: 21 Dec 2021

Peer Review: 22 Dec 2021
Accepted: 25 Jan 2022

Published (O): 05 Mar 2022

Published (P): 05 Mar 2022

\section{INTRODUCTION}

The medical graduate, to have a safe and effective clinical practice, sound knowledge of anatomy is very much essential [1]. In medical curriculum of recent times, the teaching hours of Anatomy has been grossly reduced and the faculty are facing a great challenge to teach the whole human anatomy in a very short span of time [2]. There are evidences in the literature that if the students are engaged in interactive and active sessions of learning anatomy, then the knowledge gained would be retained for a longer period of time [2]. There are several methods of teaching and learning activities in Anatomy like class room lectures, practical dissections, case based 
learning, problem based learning, animated video based embryology sessions, etc., Students have various styles of learning like visual, auditory, reading and kinesthetic. Usually students have all these components but one may be predominant.Hence it becomes a challenge for the faculty to find a common method to cater the needs of these varied students and effectively teach them in less time [3].

The medical council of India $(\mathrm{MCl})$ in its 'Vision 2015' document emphasized the importance of self directed learning (SDL) for encouraging lifelong learning skills [4].

Self directed learning is wherein the students take the responsibility for their own learning whereas the faculty become facilitators to guide them in the process of learning. This self directed learning makes them equipped to keep updated with their knowledge to become an efficient health care professional [5].

Moreover $\mathrm{MCl}$ in its document also encourages that medical education should provide more scope for learner centric approaches and active learning that help in acquiring the competencies for the Indian medical graduates [4].

In teaching anatomy it is a challenge, to provide an appropriate medium and environment for teaching for all the students $[6,7]$. Literature reveals that when an active interactive environment is created it facilitates the deep strategic learning of anatomy $[7,8]$. Many previous studies done, demonstrate that model making exercise, is a tool which helps in deep understanding of anatomy and helps in applying the knowledge effectively in their clinical practice $[9,10]$. Clay modelling provides an interesting approach towards learning anatomy. Oh et al., used clay modelling for better understanding of cross-sectional anatomy [11]. The advantage of using model making as an exercise for active learning is that it enables the students to get more idea and understanding of the three dimensional structure of various organ in a simpler way [12]. There are evidences in the literature showing that when such active model making exercises are incorporated in our routine teachings, it helps the students to remember, retain their knowledge for a longer period of time [13].

Int J Anat Res 2022, 10(1):8291-96. ISSN 2321-4287
Model making enhances the creativity and skill of the students [14]. This model making exercise will help the students to learn actively by doing the model of the structures [14].

In our study, the aim was to introduce model making as a technique of learning Anatomy which is supposed to actively engage the students and the objectives were to evaluate the student's feedback concerning their perception to the various aspects of model making, as a technique of learning anatomy.

\section{MATERIALS AND METHODS}

After obtaining ethical clearance from the institutional ethical review board, one hundred first year medical students were divided into four groups of 25 each according to their allotted dissection tables. At various phases of regional dissection in different times, each group was given a topic to make clay/ craft model accordingly. For example, the first group was asked to do 'structures under the cover of gluteus maximus' model when lower limb gluteal region dissection was being done. Second group was given cavernous sinus for the head and neck and so on. These topics of clay modeling were given to the students during the appropriate dissection session. Two days prior to the activity, six volunteers were selected among 25 and their topic for clay/ craft modeling was informed. The next day they were provided with the play dough of different colours, craft papers, coloured electrical wires, bones, glue stick and were given two hours of time to complete the model (Figure 1, 2, 3, 4, 5). The students were also free to choose any resources of their choice, atlases/text books. Simultaneously the other nineteen of the group were involved in routine dissection. This was then followed by demonstration of the model by model making group and then demonstration of structures by dissection group under the supervision of faculty. All the nineteen students in the group were allowed to handle and reassemble the structures as many times as they required.

Table 1 shows the various topics for which this activity was planned. These topics for the activity were planned on either structures difficult to be seen/remembered in dissections 
or structures important for exam purpose.

Usually at the end of each region, an examination was taken by the students on that region and an anonymous feedback was obtained from the students regarding their perceptions about the various aspects of model making as a method to learn Anatomy through a self-administered questionnaire after the exam. The questionnaire (Table 2) had six items, each item being scored on a five-point Likert rating scale. The items were developed based on previous literature and were all positively framed $[6,9,14,15]$. Pilot testing of the questionnaire was done on the first group of students. The reliability of the questionnaire was found to be satisfactory (Cronbach's alpha of 0.70). The proportion of students who responded in each category for each item was tabulated.

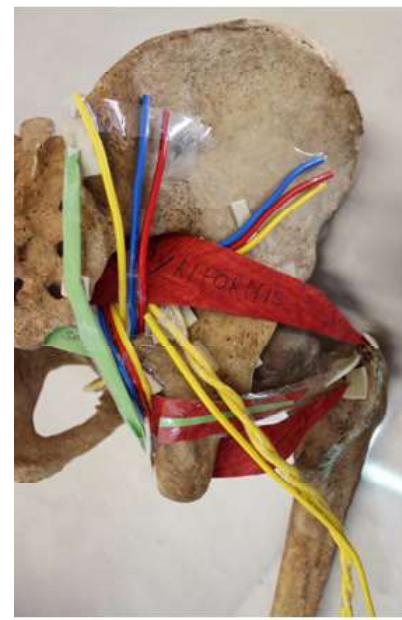

Fig. 1: The structures under the cover of gluteus maximus.

The figure shows muscles (red colour), Neuro vascular bundle(red, blue and yellow colour wires),Ligaments(light green) on the posterior aspect of the bony pelvic base right side

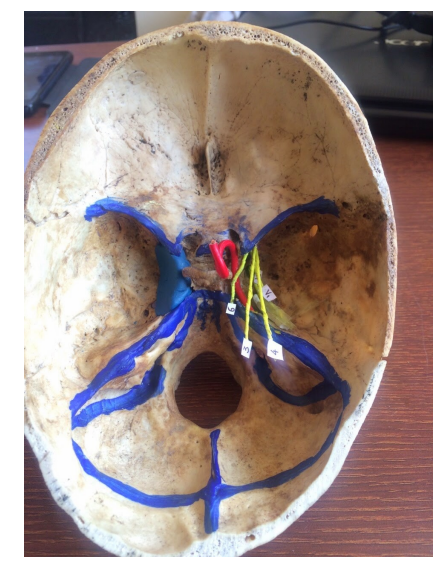

Fig. 2: Cavernous venous sinuses.

The figure shows left clay model of cavernous sinus(blue colour) and right side shows the III,IV,V,VI cranial nerves(yellow colour) and internal carotid artery(red colour)related to cavernous sinus in the middle cranial fossa

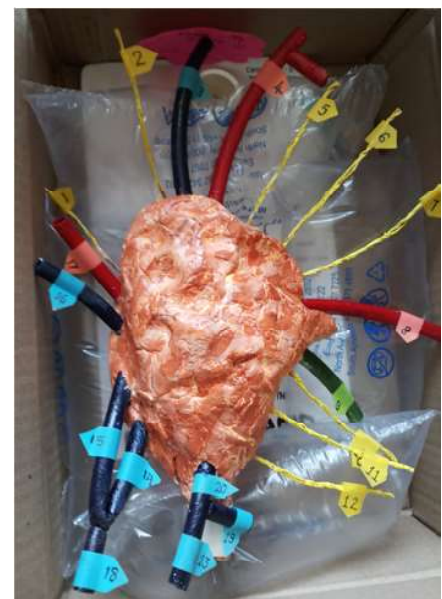

Fig. 3: Parotid gland.

The figure shows Parotid gland plaster of paris model with its borders and surfaces and the structures emerging at the periphery of the gland

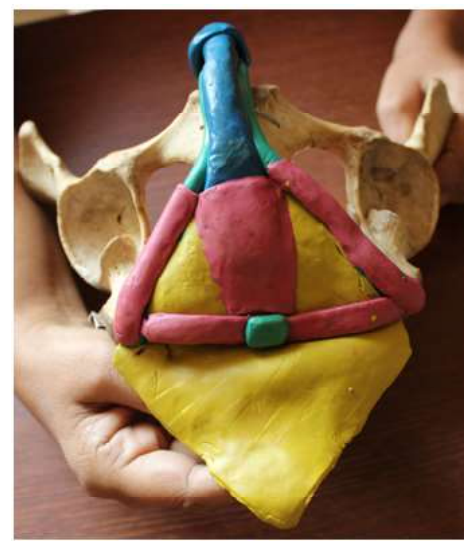

Fig. 4: Superficial perineal pouch.

The figure shows superficial muscles of male perineum(pink colour),perineal body(green colour), colles fascia(full yellow triangle), Perineal membrane(two yellow triangles) and penis(blue colour) on the inferior surface of base of bony pelvis

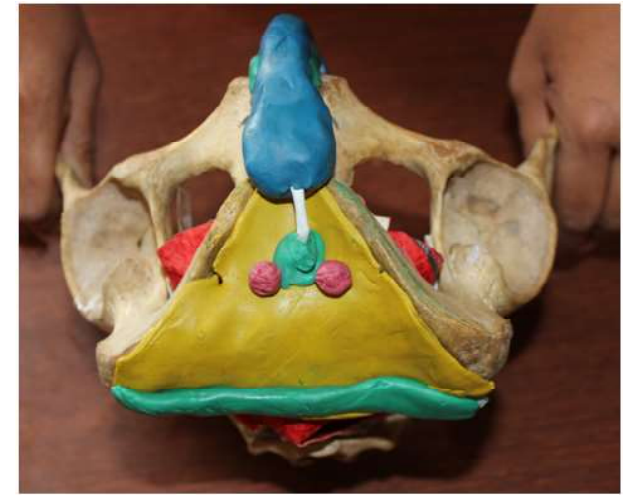

Fig. 5: Deep perineal pouch.

The figure shows deep perineal pouch of male perineum with bulbourethral glands (2 pink colour), urethra (white color) urethral sphincter (green clay surrounding urethra) and penis (blue clay) on the inferior surface of bony pelvis 
Table 1: Topics of model making activity in different region.

\begin{tabular}{|c|l|l|} 
S.No & Dissection Region & \multicolumn{1}{c|}{ Topic for model making activity } \\
\hline $\mathbf{1}$ & Lower limb & $\begin{array}{l}\text { structures under the cover of } \\
\text { gluteus maximus }\end{array}$ \\
\hline $\mathbf{2}$ & Head \& Neck & Cavernous venous sinuses \\
\hline $\mathbf{3}$ & Head \& Neck & Parotid gland \\
\hline $\mathbf{4}$ & Pelvis & $\begin{array}{l}\text { Superficial perineal pouch and } \\
\text { Deep perineal pouches }\end{array}$ \\
\hline
\end{tabular}

Table 2: Students' responses to the questionnaire regarding Model making as a method of learning in Anatomy.

\begin{tabular}{|c|c|c|c|c|c|c|}
\hline S.no & $\begin{array}{l}\text { Item } \\
\text { Please respond to the following }\end{array}$ & $\begin{array}{l}\text { Strongly agree } \\
\text { N (\%) }\end{array}$ & $\begin{array}{c}\text { Agree } N \\
(\%)\end{array}$ & $\begin{array}{l}\text { Neutral N } \\
\text { (\%) }\end{array}$ & $\begin{array}{l}\text { Disagree N } \\
\text { (\%) }\end{array}$ & $\begin{array}{c}\text { Strongly disagree } \\
\text { N (\%) }\end{array}$ \\
\hline 1 & $\begin{array}{l}\text { Model making as a tool was } \\
\text { useful to learn anatomy }\end{array}$ & $63(67.74)$ & $25(26.88)$ & $5(5.37)$ & - & - \\
\hline 2 & $\begin{array}{l}\text { Brought in more interaction } \\
\text { among the students. }\end{array}$ & $52(55.91)$ & $29(31.18)$ & $10(10.75)$ & $1(1.07)$ & $1(1.07)$ \\
\hline 3 & $\begin{array}{l}\text { Helped in recollecting the } \\
\text { structures during the exam }\end{array}$ & $45(48.38)$ & $37(39.78)$ & $10(10.75)$ & $1(1.07)$ & - \\
\hline 4 & $\begin{array}{l}\text { Learning by doing/reassembling } \\
\text { helps in retaining the knowledge } \\
\text { obtained }\end{array}$ & $52(55.91)$ & $33(35.48)$ & $8(8.60)$ & - & - \\
\hline 5 & Can be used along with dissection. & $48(51.61)$ & $34(36.55)$ & $7(7.52)$ & $3(3.22)$ & $1(1.07)$ \\
\hline 6* & $\begin{array}{l}\text { Teach other topic as well by this } \\
\text { method \& can be continued for } \\
\text { further batches. }\end{array}$ & $57(61.29)$ & 29(31.18) & $6(6.45)$ & - & - \\
\hline
\end{tabular}

$*^{\text {th }}$ item only 92 responses considered (as in one form more than one response was ticked)

\section{RESULTS}

Of the hundred students only ninety three completed the questionnaire. Table 2 summarizes the responses of the students. Question no. 6 only 92 responses taken as in one form multiple responses were ticked

\section{DISCUSSION}

The present study showed that a large majority of the students had positive perceptions about the model making activity to learn anatomy. The results of our study are comparable with other studies conducted as shown in Table 3. Present study and another study on 140 medical students [14], revealed that $95 \%$ of students reported that the model making exercise was a very useful tool in learning anatomy. Claudia in her study got $81 \%$ of health science students [15] to have a positive feedback on model making with regard to the long term memory of subject learned whereas in our study around $91 \%$ students perceived the long term retention. A study on 100 medical students to evaluate the long term retention of knowledge acquired through model making activity showed that the mean score of model making group was greater compared to control group(only lecture and no activity) when scores were evaluated immediately after the class, after 15 days, and even after 30 days [16].Mary Ellan [9] in her study found the least percentage of $77 \%$ of students felt that model making had more interaction among the students compared to conventional method and in other study students reported [14], interaction was $100 \%$ whereas in present study it is $87 \%$.

Oh etal., in their study [11], on clay modelling for learning cross sectional anatomy reason out that the positive feedback for model making activity, was that the students were able to understand three-dimensional (3D) structures and cross-sectional anatomy more easily after making the model with $\mathrm{CT}$ or MR images (58\%). The active student participation (26\%) and the interest generated by model making (16\%) were also some reasons, the students found model making to be interesting and useful.

The study on the health sciences students who were involved in innovative modes of 
Table 3: Comparison of the results of the present study with other studies that utilized model making as a learning tool $[14,9,6,15]$.

\begin{tabular}{|c|c|c|c|c|c|c|}
\hline S.No & Items & $\begin{array}{l}\text { Nagaraj et al., } \\
\text { ( } n=140) \\
\text { (\%) agree } \\
\text { (INDIA) } \\
\text { (Anatomy) } \\
\text { (medical students) }\end{array}$ & $\begin{array}{c}\text { Mary Ellen et al., } \\
\text { ( } n=110) \\
\text { (\%) agree } \\
\text { (USA) } \\
\text { (Anatomy\&Physiology) } \\
\text { (nursing\&Allied students) }\end{array}$ & $\begin{array}{l}\text { Ayman Mustafa et al } \\
\text { ( } n=246 \text { ) } \\
\text { (\%) agree } \\
\text { (Jordan) } \\
\text { (Anatomy) } \\
\text { (medical students) }\end{array}$ & $\begin{array}{c}\text { Claudia et.,al } \\
\text { ( } n=176) \\
\text { (\%) agree } \\
\text { (Australia) } \\
\text { (Anatomy) } \\
\text { (Health science students) }\end{array}$ & $\begin{array}{c}\text { Present study } \\
(n=93) \\
(\% \mathrm{SA}+\mathrm{A}) \\
\text { (medical students) }\end{array}$ \\
\hline 1 & $\begin{array}{l}\text { Model making Method used in learning } \\
\text { anatomy was useful. }\end{array}$ & 95 & 72.7 & 87.3 & 83 & 94.62 \\
\hline 2 & $\begin{array}{l}\text { Teach other topic as well by this method \& can } \\
\text { be continued for further batches }\end{array}$ & 90 & 84 & - & - & 92.47 \\
\hline 3 & Brought in more interaction among the students. & 100 & 77.3 & 92.4 & - & 87.09 \\
\hline 4 & Learning by doing helps in long term memory & - & - & - & 81 & 91.39 \\
\hline
\end{tabular}

learning Anatomy were found more likely to enjoy the subject compared to the medical students (who were not involved). In fact the health science students also had a greater experiential learning and increased interest in the course [15]. These students opined that these methodologies helps in better understanding of the subject and can be put for clinical practice in later years [15]. Myers et al. (2001) on conducting a study on post graduates, showed that clay modelling combined with a lecture was way more effective in long term memory and recall of anatomy rather than the lecture alone [17].

On comparing the teaching methodologies of gross dissection and model making, Mary Ellen [9], showed that both methodologies were equally effective with respect to knowledge gained, whereas Motoike [18], described that dissection is wherein the structures are dissected from superficial to deep whereas in model making it is a skillful activity of construction of structures from deep to superficial plane. The author also emphasized in his study that for skillful construction of the clay model, not only creativity is required more of deeper understanding of the subject is very essential for the final outcome of a near perfect model [18]. He also concluded that the clay-modeling group were better in identifying human muscles on human models rather than the group who conducted dissection on cat [18]. In a study on hundred medical students, the main aim of the author was to highlight the use of play dough in modeling the nervous tracts for understanding the physiology and also to compare the outcomes of such active learning by modeling over passive learning in medical students [16]. The results demonstrate that model making activity helps in retaining the knowledge gained for a longer period of time [16]. Inspite of students being interested and understand the subject and retain it for a longer period of time,there are some limitations in this model making methodology of teaching/learning anatomy, that it is a time consuming process and models can't be done for all topics and only students those who were interested participated in model making activity so there are chances of bias. Moreover the difficulty level of the topics for model making were not uniform.

\section{CONCLUSION}

Anatomy can be well learned with interest and fun, better understood and retained for a longer time if the model making is used as an adjuvant for dissection. When these activities are incorporated in our conventional method of teaching it provides a much more engaging, motivating, inspiring, inquisitive and enjoyable environment for student learning. These innovative methods make sure that the students achieve the desired learning outcomes, and they become more confident learners laying a path for lifelong self directed learning.

\section{ORCID:}

Uma SV- https://orcid.org/0000-0002-7833-3695

\section{ACKNOWLEDGEMENTS}

I would like to acknowledge the support rendered by my Head of the department, colleagues, non-teaching staff, attenders and students for this study to be conducted. 


\section{Conflicts of Interests: None}

\section{REFERENCES}

[1]. Bergman EM, van der Vleuten CPM, Scherpbier AJJ a. Why don't they know enough about anatomy? A narrative review. Med Teach. 2011;33(2):403-9.

[2]. Sharadkumar Pralhad Sawant, Shaheen Rizvi. Teaching anatomy to undergraduate students. Int J Anat Res 2015;3(2):1212-15.

[3]. Vikas Seth, Prerna Upadhyaya, Mushtaq Ahmad, Vijay Moghe. PowerPoint or chalk and talk:Perceptions of medical students versus dental students in a medical college in India. AdvMedEducPract. 2010;1:11-16.

[4]. MCI BOOKLET; VISION 2015. Available from http:/ /www.mciindia.org/tools/announcement/MCI booklet.pdf

[5]. School of Education at Johns Hopkins UniversityThoughts on Self-Directed Learning in Medical Schools: Making Students More Responsible [Internet]. 2015. p. 1-6. Available from: http:// education.jhu.edu/PD/newhorizons/ lifelonglearning/higher-education/medicalschools/

[6]. Mustafa AG, Allouh MZ, Mustafa IG, Hoja IM. Anatomy learning styles and strategies among Jordanian and Malaysian medical students: The impact of culture on learning anatomy. SurgRadiol Anat. 2013;35(5):435-41.

[7]. "Understanding Your Learning Style". Wilfrid LayrierUniversity.Study skills \& supplemental instruction centre 2008;1-10.

[8]. Friedman BD. Types of Learners. How to teach Eff. 2013;11-5.

[9]. DeHoff ME, Clark KL, Meganathan K. Learning outcomes and student-perceived value of clay modeling and cat dissection in undergraduate human anatomy and physiology. Am J Physiol - Adv Physiol Educ. 2011;35(1):68-75.
[10]. Krontiris-Litowitz J. Using manipulatives to improve learning in the undergraduate neurophysiology curriculum. Adv Physiol Educ 2003;27:109-119.

[11]. Oh CS, Kim JY, Choe YH. Learning of cross-sectional anatomy using clay models. AnatSci Educ. 2009;2(4):156-9.

[12]. Gilbert JK, Boulter CJ. Learning science through models and modeling. In: International Handbook of Science Education, edited by Fraser BJ, Tobin KG. London: Kluwer Academic, 1998, p. 53-56

[13]. Mayer RE. The promise of multimedia learning: using the same instructional design methods across different media. Learn Instr. 2003;13(2):125-39.

[14]. Mallashetty N, Itagi V, Angadi a V. Model making exercise- A new tool for teaching \& learning anatomy and perception of students towards it. 2015;3(1):34-6.

[15]. Claudia Diaz. For stimulating multidisciplinary first year students to learn Anatomy for life via innovative, pro-active approaches to improve engagement and learning outcomes. Citations for Outstanding Contributions to Student Learning. 2011;1-4.

[16]. Herur A, Kolagi S, Chinagudi S, Manjula R, Patil S. Active learning by play dough modeling in the medical profession. Am J Physiol - AdvPhysiol Educ. 2011;35(2):241-3.

[17]. Myers DL.Pelvic anatomy for obstetrics and gynecology residents: an experimental study using clay models. ObstetGynecol 2001;97:321-324.

[18]. Motoike HK, O'Kane RL, Lenchner E, Haspel C. Clay modeling as a method to learn human muscles: a community college study. AnatSciEduc 2009;2: 19-23.

How to cite this article:

Uma SV. Model Making, An Interesting Method of Learning Anatomy: Students' perceptions. Int J Anat Res 2022;10(1):82918296. DOI: $10.16965 /$ ijar.2021.210 